\title{
Nghiên cứu các nhân tố ảnh hưởng đến ý định khởi nghiệp của sinh viên Trường Đại học Tiền Giang
}

\section{A study of factors affecting Tien Giang University students' entrepreneurial intention}

\author{
Võ Văn Hiền ${ }^{1}$, Lê Hoàng Vân Trang ${ }^{1 *}$ \\ ${ }^{1}$ Trường Đại học Tiền Giang, Việt Nam \\ *Tác giả liên hệ, Email: lehoangvantrang@tgu.edu.vn
}

\begin{tabular}{|c|c|}
\hline THÔNG TIN & TÓM TẮT \\
\hline $\begin{array}{l}\text { DOI:10.46223/HCMCOUJS. } \\
\text { econ.vi.16.2.578.2021 }\end{array}$ & $\begin{array}{l}\text { Mục đích của bài viết là xác định các nhân tố ảnh hưởng } \\
\text { đến ý định khởi nghiệp của sinh viên Trường Đại học Tiền } \\
\text { Giang. Nghiên cứu dựa trên lý thuyết hành vi dự định của Ajzen } \\
\text { (1991) kết hợp với các nghiên cứu liên quan để xây dựng mô } \\
\text { hình nghiên cứu đề xuất gồm bảy nhân tố tác động đến ý định } \\
\text { khởi nghiệp. Nghiên cứu định tính nhằm điều chỉnh mô hình và } \\
\text { thang đo sơ bộ, hình thành mô hình và thang đo nghiên cứu }\end{array}$ \\
\hline Ngày nhận: 09/07/2020 & $\begin{array}{l}\text { chính thức. Nghiên cứu định lượng được tiến hành để kiểm định } \\
\text { độ tin cậy thang đo và đo lường mức độ ảnh hưởng của các }\end{array}$ \\
\hline Ngày nhận lại: 22/09/2020 & nhân tố đến ý định khởi nghiệp thông qua phân tích hồi quy \\
\hline Duyệt đăng: 30/10/2020 & $\begin{array}{l}\text { tuyến tính đa biến. Kết quả nghiên cứu chỉ ra rằng có năm nhân } \\
\text { tố ảnh hưởng đến ý định khởi nghiệp của sinh viên, sắp xếp theo } \\
\text { mức độ ảnh hưởng giảm dần là: (1) đặc điểm tính cách, (2) giáo } \\
\text { dục khởi nghiệp, (3) kinh nghiệm, (4) nhận thức kiểm soát hành } \\
\text { vi và (5) quy chuẩn chủ quan. Dựa trên kết quả nghiên cứu, một } \\
\text { số hàm ý quản trị liên quan đến } 5 \text { nhân tố ảnh hưởng cũng được } \\
\text { đưa ra nhằm nâng cao ý định khởi nghiệp của sinh viên nhà }\end{array}$ \\
\hline Tù khóa: & trường, đồng thời đề xuất hướng nghiên cứu cho tương lai. \\
\hline
\end{tabular}

ý định khởi nghiệp; kinh nghiệm; tính cách; sinh viên

Keywords:

entrepreneurial intention; experience; personality; students

\section{ABSTRACT}

The objective of this paper is to identify the factors affecting Tien Giang university students' entrepreneurial intention. The study is based on the theory of Planned Behavior (Ajzen, 1991) and previous relevant empirical studies to build a proposed research model which included seven factors influencing students' entrepreneurial intention. Qualitative research corrected the research model and preliminary research scale and formed the official research model and scale. Quantitative research was used to test the scale's reliability and measure the impact of factors on entrepreneurial intention through the multivariate linear regression analysis. Study results indicated that five factors were being sorted by the level of diminishing influence: (1) personality traits, entrepreneurship education, (3) experience, (4) perceived behavioral control, and (5) subjective norm. Besides, the study 


\begin{abstract}
also showed differences relevant to students' entrepreneurial intention by gender. Based on the study outcomes, the paper was concluded by giving some managerial implications relevant to 05 influencing factors to increase students' entrepreneurial intention in the considered area and proposing research directions for the future.
\end{abstract}

\title{
1. Giới thiệu
}

Thời gian qua, khởi nghiệp được xem là một trong những hoạt động có tầm ảnh hưởng nhất định đến sự phát triển của đất nước và là một giải pháp hữu hiệu cho tình trạng thất nghiệp đang ngày càng gia tăng. Nhiều chính sách khuyến khích khởi nghiệp đối với thanh niên đã được Chính phủ ban hành. Trong số đó, những đề án phát huy tinh thần khởi nghiệp trong sinh viên luôn được chú trọng, mà điển hình là đề án "Hỗ trợ học sinh, sinh viên khởi nghiệp đến năm 2025" (gọi tắt là Đề án 1665) được Thủ tướng Chính phủ ký quyết định ban hành ngày 30/10/2017. Có thể nói, sinh viên với sự trẻ trung, năng động và nguồn ý tưởng khởi nghiệp đa dạng sẽ là những nhà khởi nghiệp tiềm năng sau này.

Xét riêng Trường Đại học Tiền Giang, bên cạnh sứ mạng đào tạo nguồn nhân lực trình độ cao và mang đến cho người học cơ hội nghề nghiệp để thăng tiến, việc truyền cảm hứng khởi nghiệp và hình thành năng lực khởi nghiệp trong các thế hệ sinh viên cũng được nhà trường chú trọng. Trong năm 2019, trường đã phối hợp với Tập đoàn Trung Nguyên Legend khởi xướng chương trình "Hành trình từ trái tim - Hành trình lập chí vĩ đại - Khởi nghiệp kiến quốc". Bên cạnh đó, bắt đầu từ năm 2012 đến nay, cuộc thi "Sinh viên khởi nghiệp" được tổ chức thường lệ hàng năm như một hình thức mà nhà trường góp phần tạo môi trường khích lệ khởi nghiệp chung trong xã hội.

Tuy nhiên trong thực tế, các ý tưởng kinh doanh của sinh viên chỉ dừng lại ở mức ý tưởng. Hầu hết sinh viên chưa mạnh dạn thực hiện khởi nghiệp sau khi ra trường, kể cả sinh viên thuộc nhóm ngành kinh tế. Theo phòng công tác sinh viên và trung tâm khảo thí Trường Đại học Tiền Giang (2019), số sinh viên khởi nghiệp kinh doanh hay tự tạo việc làm cho mình chỉ chiếm khoảng $8.5 \%$. Số liệu có được từ việc thực hiện khảo sát việc làm của 487 cựu sinh viên sau một năm ra trường (các sinh viên tốt nghiệp vào tháng 09/2018). Điều này chứng tỏ đã có sinh viên của trường khởi sự kinh doanh và tự tạo việc làm cho bản thân nhưng tỷ lệ vẫn còn rất thấp.

Theo Krueger và Brazeal (1994), ý định cho khởi nghiệp chính là tiền đề cho hành vi khởi nghiệp. Điều này khẳng định việc nghiên cứu ý định khởi nghiệp là rất quan trọng và thể hiện nỗ lực khuyến khích các hoạt động tự kinh doanh. Thực chất, các bạn sinh viên muốn khởi nghiệp thành công thì phải có sự đầu tư tìm hiểu kỹ lưỡng ngay từ lúc ban đầu hình thành ý định. Nhiều nghiên cứu nước ngoài về các yếu tố ảnh hưởng ý định khởi nghiệp của sinh viên được thực hiện như các nghiên cứu của Ambad và Damit (2016); Suan, Ai, Raman, Loon, và Tanumihardja (2011); Zhang, Duysters, và Cloodt (2014)... Việt Nam cũng có một số nghiên cứu cùng lĩnh vực nhưng chủ yếu đều thực hiện tại các trường đại học ở các thành phố lớn như Thành phố Hồ Chí Minh (TP. HCM) hay Cần Thơ, và hiện tại chưa có một nghiên cứu đầy đủ nào về ý định khởi nghiệp của sinh viên Trường Đại học Tiền Giang. Ngoài ra, tuỳ theo đặc điểm của từng trường đại học cũng như hoàn cảnh từng địa phương mà các yếu tố ảnh hưởng đến ý định khởi nghiệp của sinh viên cũng sẽ được tiếp cận theo những khía cạnh khác nhau. Với những lý do trên, việc triển khai thực hiện đề tài "Nghiên cứu các nhân tố ảnh hưởng đến ý định khởi nghiệp của sinh viên Trường Đại học Tiền Giang" là cần thiết. Kết quả nghiên cứu sẽ mang đến cho lãnh đạo nhà trường cái nhìn toàn diện về những yếu tố nào thật sự ảnh hưởng đến ý 
định khởi nghiệp của sinh viên, từ đó đưa ra những định hướng hỗ trợ phù hợp, giúp sinh viên có được những kiến thức, kỹ năng và thái độ cần thiết làm hành trang khi khởi nghiệp sau này.

Ngoài phần tóm tắt, giới thiệu và tài liệu tham khảo thì nội dung bài nghiên cứu bao gồm cơ sở lý thuyêt, phương pháp nghiên cứu, kết quả nghiên cứu và thảo luận, kết luận và các hàm ý quản trị.

\section{Cơ sở lý thuyết}

\subsection{Khởi nghiệp (Entrepreneurship)}

Các quan điểm về khởi nghiệp luôn khác nhau và định nghĩa khởi nghiệp không là duy nhất. MacMillan (1993) định nghĩa khởi nghiệp là việc cá nhân chấp nhận mọi rủi ro để tạo lập doanh nghiệp mới hoặc mở cửa hàng kinh doanh vì mục đích lợi nhuận và làm giàu. Hisrich và Drovensek (2002) cho rằng khởi nghiệp là quá trình tạo ra một cái gì đó mới mẻ, có giá trị bằng cách dành thời gian và nỗ lực cần thiết để đạt được sự độc lập về tiền tệ, trong đó có những rủi ro về tài chính, tâm linh và xã hội kèm theo. Theo Nga và Shamuganathan (2010), khởi nghiệp là sự theo đuổi các cơ hội làm giàu về mặt kinh tế thông qua các sáng kiến hay các ý tưởng mới của cá nhân trong môi trường hoạt động không chắc chắn với các nguồn lực hữu hình giới hạn.

Trong nghiên cứu này, khởi nghiệp sẽ được hiểu là sự tạo dựng một công việc kinh doanh mới hay thành lập một doanh nghiệp mới thông qua những ý tưởng kinh doanh sáng tạo, nhận diện và tận dụng được các cơ hội để đạt được sự hài lòng trong việc kinh doanh của chính mình (Koe, Sa'ari, Majid, \& Ismail, 2012). Quan điểm này dễ hiểu và có sự tương đồng với các quan điểm về khởi nghiệp trước đó.

\section{2. Ý định khởi nghiệp (Entrepreneurial Intention)}

Bird (1988) quan niệm ý định khởi nghiệp của một cá nhân là trạng thái tâm trí, trong đó hướng đến việc hình thành một hoạt động kinh doanh mới hay tạo lập một doanh nghiệp mới. Ý định khởi nghiệp cũng được định nghĩa là ý định của một cá nhân để bắt đầu một doanh nghiệp (Souitaris, Zerbinati, \& Al-Laham, 2007). Kuckertz và Wagner (2010) khẳng định ý định khởi nghiệp bắt nguồn từ việc nhận ra cơ hội, tận dụng các nguồn lực có sẵn và sự hỗ trợ của môi trường để tạo lập doanh nghiệp. Zain, Akram, và Ghani (2010) cho rằng ý định khởi nghiệp thường liên quan đến nội tâm, hoài bão và cảm giác của cá nhân đối với việc "đứng trên đôi chân của mình".

Nghiên cứu của Dohse và Walter (2012) đã đưa ra một khái niệm súc tích và gần gũi hơn so với các nghiên cứu trước về ý định khởi nghiệp, trong đó ý định khởi nghiệp là trạng thái của tâm trí trong việc sẵn sàng thực hiện tự kinh doanh, tự tạo việc làm hoặc thành lập doanh nghiệp mới. Ý định khởi nghiệp trong phạm vi nghiên cứu của bài báo này cũng được hiểu theo quan điểm của Dohse và Walter (2012).

\subsection{Lý thuyết về hành vi dụ định của Ajzen (1991)}

Lý thuyết về hành vi dự định của Ajzen (1991) - Ajzen's Theory of Planned Behavior (TPB) - là một sự mở rộng của lý thuyết hành động hợp lý (Theory of reasoned action) mà Ajzen đã từng đưa ra trước đó, nhằm khắc phục những hạn chế của mô hình ban đầu trong việc giải quyết kiểm soát hành vi. Lý thuyết này xác định ba tiền đề của ý định: thái độ đối với hành vi (attitude toward the behavior hay perceived attitude), các quy chuẩn chủ quan (subjective norm) và nhận thức kiểm soát hành vi (perceived behaviorial control).

Thái độ đối với hành vi đề cập đến mức độ mà một người đánh giá về hành vi đang được nói đến là có lợi hay không có lợi. "Các quy chuẩn chủ quan" đề cập đển nhận thức của cá nhân về các áp lực xã hội có ảnh hưởng đến việc thực hiện hoặc không thực hiện hành vi. Thêm vào đó, 
Ajzen (1991) cũng cho rằng "thái độ đối với hành vi” và các "quy chuẩn chủ quan" phản ánh "nhận thức mong muốn" của việc thực hiện hành vi. Còn "nhận thức kiểm soát hành vi” phản ánh nhận thức rằng hành vi này có thể kiểm soát được một cách cá nhân hay không. Nói cách khác, "nhận thức kiểm soát hành vi” đề cập đến nhận thức của cá nhân về sự dễ dàng hoặc khó khăn trong việc thực hiện hành vi. Đây là yếu tố được Ajzen (1991) xem là quan trọng trong mô hình hành vi dự định, đồng thời cho thấy điểm khác biệt so với thuyết hành động hợp lý trước đó.

Mô hình của Ajzen (1991) được sử dụng khá phổ biến trong nhiều nghiên cứu liên quan đến ý định khởi nghiệp của cá nhân. Trong nghiên cứu này, các yếu tố trong mô hình của Ajzen (1991) cũng được sử dụng để xây dựng mô hình các nhân tố ảnh hưởng đến ý định khởi nghiệp của sinh viên.

\subsection{Tổng quan các nghiên cứu về các nhân tố ảnh hưởng đến ý định khởi nghiệp của sinh viên}

\subsubsection{Nghiên cúu nước ngoài}

Suan và cộng sự (2011) nghiên cứu về ý định khởi nghiệp của 200 sinh viên đại học Malaysia. Nghiên cứu này sử dụng lý thuyết sự kiện khởi nghiệp của Shapero và Sokol (1982) kết hợp một số yếu tố khác phù hợp với hoàn cảnh nghiên cứu để xây dựng mô hình nghiên cứu. Kết quả nghiên cứu cho thấy, ngoại trừ "gia đình và bối cảnh cá nhân”, các yếu tố còn lại là đặc điểm tính cách, giáo dục, kinh nghiệm và nhận thức mong muốn đều thể hiện sự tác động tích cực đến ý định khởi nghiệp. Hạn chế của nghiên cứu là mẫu khảo sát nhỏ với 200 sinh viên và bỏ qua việc xem xét yếu tố thái độ đối với hành vi có ảnh hưởng thế nào đến ý định khởi nghiệp.

Nghiên cứu của Liñán, Rodríguez-Cohard, và Rueda-Cantuche (2011) tại Trường đại học Pablo Olavide và Seville (Tây Ban Nha) xác định giáo dục khởi nghiệp, thái độ cá nhân, quy chuẩn xã hội và nhận thức tính khả thi đều có sự tác động tích cực đến ý định khởi nghiệp của sinh viên. Nghiên cứu có hạn chế là chỉ khảo sát trên đối tượng sinh viên thuộc các chuyên ngành kinh tế (kinh doanh và kinh tế học) mà bỏ qua sinh viên các nhóm ngành văn hóa hay xã hội.

Còn kết quả nghiên cứu của Zhang và cộng sự (2014) tại 10 trường đại học ở Trung Quốc thể hiện ngoài yếu tố "nhận thức tính khả thi" không có sự ảnh hưởng thì ba yếu tố còn lại là nhận thức mong muốn, kinh nghiệm và giáo dục khởi nghiệp đều có ảnh hưởng tích cực đến ý định khởi nghiệp. Hạn chế của nghiên cứu là chỉ thực hiện khảo sát đối với sinh viên đại học mà bỏ qua các đối tượng khác (chẳng hạn sinh viên cao đẳng, học sinh trung cấp).

Cùng lĩnh vực, nghiên cứu của Sabah (2016) được thực hiện thông qua khảo sát 528 sinh viên năm ba và năm tư ngành Quản trị kinh doanh (232 nam và 296 nữ) đến từ ba thành phố của Thổ Nhĩ Kỳ: Istanbul, Ankara và İzmir. Lý thuyết hành vi dự định (Ajzen, 1991) được sử dụng để xây dựng mô hình nghiên cứu. Kết quả nghiên cứu thể hiện các yếu tố trong mô hình đều có ảnh hưởng tích cực đến ý định khởi nghiệp của sinh viên, gồm thái độ đối với hành vi, nhận thức kiểm soát hành vi và quy chuẩn chủ quan.

Còn Ambad và Damit (2016) thực hiện nghiên cứu về các nhân tố tác động đến ý định khởi nghiệp của sinh viên tại Malaysia thông qua khảo sát 351 sinh viên đại học đến từ Trường Đại học cộng đồng Malaysia. Kết quả nghiên cứu cho thấy có ba nhân tố có sự ảnh hưởng đến ý định khởi nghiệp của sinh viên là thái độ cá nhân (ảnh hưởng mạnh nhất), quy chuẩn chủ quan và nhận thức kiểm soát hành vi.

\subsubsection{Nghiên cúu trong nước}

Hoang và Bui (2013) đã thực hiện nghiên cứu về ý định khởi nghiệp của nữ học viên đang theo học chuyên ngành MBA tại TP. HCM. Kết quả nghiên cứu thể hiện các yếu tố như 
nguồn vốn, đặc điểm cá nhân, hỗ trợ từ gia đình đều có sự ảnh hưởng tích cực đến ý định khởi nghiệp. Hạn chế của nghiên cứu là chỉ thực hiện khảo sát tại TP. HCM ở ba trường đại học mà bỏ qua khảo sát các nữ học viên MBA tại các trung tâm đào tạo bên ngoài khác (quốc tế, đào tạo ngắn hạn...).

Phan và Giang (2015) xây dựng mô hình ý định khởi nghiệp của sinh viên khoa kinh tế và Quản trị kinh doanh (QTKD) Trường Đại học Cần Thơ với các yếu tố tác động gồm: thái độ, quy chuẩn chủ quan, nhận thức kiểm soát hành vi, giáo dục và nguồn vốn. Tuy nhiên mô hình nghiên cứu đã bỏ qua một số nhân tố khác, chẳng hạn như đặc điểm tính cách và kinh nghiệm.

Do (2016) nghiên cứu ý định khởi nghiệp kinh doanh của sinh viên QTKD tại Trường Đại học Lao động - Xã hội, cơ sở TP. HCM. Kết quả nghiên cứu cho thấy cả bốn yếu tố: tính cách cá nhân, giáo dục và đào tạo, kinh nghiệm và nguồn vốn đều ảnh hưởng tích cực đến ý định khởi nghiệp của sinh viên. Hạn chế của nghiên cứu là bỏ qua sự tác động của một số yếu tố khác như thái độ hoặc nhận thức của sinh viên về khởi nghiệp kinh doanh và bỏ qua các sinh viên các ngành khác.

Tóm lại, với những hạn chế đã có ở các nghiên cứu trước và sự khuyến khích thực hiện nghiên cứu về ý định khởi nghiệp của sinh viên ở nhiều vùng khác nhau do các nền văn hóa khác nhau thì sẽ cho kết quả nghiên cứu khác nhau (Sabah, 2016), nghiên cứu này là cần thiết thực hiện. Nghiên cứu thực hiện trên đối tượng khảo sát là sinh viên năm cuối bậc đại học và cao đẳng thuộc tất cả các ngành đang được đào tạo tại trường. Mô hình nghiên cứu được xây dựng dựa theo lý thuyết của Ajzen (1991), nhưng có bổ sung các yếu tố từ các nghiên cứu trước sao cho phù hợp.

\subsection{Giả thuyết về sụ ảnh hưởng của các nhân tố đến ý định khởi nghiệp}

\subsubsection{Thái độ đối với hành vi (Attitude toward the behavior)}

Ajzen (1991) định nghĩa thái độ đối với hành vi là nhận thức về nhu cầu cá nhân đối với việc thực hiện hành vi. Đây cũng là mức độ mà cá nhân đánh giá hành vi được thực hiện có lợi hay không có lợi. Trong nghiên cứu này, hành vi được đề cập là hành vi khởi nghiệp. Autio, Keeley, Klofsten, Parker, và Hay (2001) khi nghiên cứu về ý định khởi nghiệp của sinh viên tại một số trường đại học ở các nước Bắc Âu và Mỹ đã kết luận rằng thái độ đối với hành vi là yếu tố có tầm ảnh hưởng tích cực quan trọng thứ hai đối với ý định khởi nghiệp. Tương tự, nghiên cứu của Lüthje và Franke (2003) cũng cho rằng thái độ đối với hành vi có ảnh hưởng tích cực và mạnh mẽ lên ý định khởi nghiệp của sinh viên. Còn kết quả nghiên cứu của Liñán và Chen (2009) tại Tây Ban Nha và Đài Loan thể hiện sự tác động của thái độ đối với hành vi lên ý định khởi nghiệp là một sự tác động cùng chiều, trong đó, thái độ của sinh viên tại Tây Ban Nha có mức độ ảnh hưởng mạnh nhất đến ý định khởi nghiệp. Từ các luận điểm trên, nghiên cứu đề xuất giả thuyết $\mathrm{H} 1$ như sau:

Giả thuyết H1: Thái độ đối với hành vi có ảnh hương tích cực đến ý định khởi nghiệp của sinh viên

\subsubsection{Quy chuẩn chủ quan (Subjective norm)}

Quy chuẩn chủ quan được định nghĩa là các áp lực xã hội đến từ gia đình, bạn bè, người thân hay những người quan trọng đối với cá nhân..., áp lực này có thể là sự kỳ vọng, ủng hộ hoặc không ủng hộ thực hiện hành vi khởi nghiệp, từ đó dẫn đến việc cá nhân sẽ quyết định thực hiện hoặc không thực hiện hành vi sau này (Ajzen, 1991). Bird (1988) kết luận một cá nhân sẽ lựa chọn thực hiện hành vi theo cách mà họ cảm nhận rằng những người khác trong xã hội mong chờ họ. Nghiên cứu của Autio và cộng sự (2001) hay nghiên cứu của Gird và Bagraim (2008) đều thể hiện sự tác động tích cực của quy chuẩn chủ quan đến ý định khởi nghiệp, mặc dù mức 
độ ảnh hưởng không là mạnh mẽ nhất. Dựa vào các quan điểm trên, nghiên cứu đề xuất giải thuyết $\mathrm{H} 2$ như sau:

Giả thuyết H2: Quy chuẩn chủ quan có ảnh hương tích cực đến ý định khởi nghiệp của sinh viên

\subsubsection{Nhận thức kiểm soát hành vi (Perceived behavioral control)}

Theo Ajzen (1991), nhận thức kiểm soát hành vi được định nghĩa là quan niệm của cá nhân về sự dễ dàng hoặc khó khăn trong việc thực hiện hành vi, có liên quan đến những kinh nghiệm trong quá khứ cũng như dự đoán những trở ngại trong tương lai. Trong một bài phân tích tổng hợp của 185 nghiên cứu thực nghiệm, Armitage và Conner (2001) đã kết luận, nhận thức kiểm soát hành vi trong lý thuyết hành vi dự định rất có hiệu quả đối với việc thúc đẩy cả về ý định lẫn hành vi khởi nghiệp của cá nhân. Khi thực hiện nghiên cứu về mối quan hệ giữa thuyết hành vi dự định, các yếu tố môi trường, các yếu tố nhân khẩu học với ý định khởi nghiệp của sinh viên tại Kenya, Amos và Alex (2014) đã chỉ ra rằng nhận thức kiểm soát hành vi là yếu tố có ý nghĩa cũng như ảnh hưởng tích cực đến biến phụ thuộc. Trước đó, nghiên cứu của Gird và Bagraim (2008) cũng cho một kết quả tương tự về tác động dương của nhận thức kiểm soát hành vi lên ý định khởi nghiệp của sinh viên. Dựa trên các luận điểm này, nghiên cứu đề xuất giả thuyết H3 như sau:

Giả thuyết H3: Nhận thức kiểm soát hành vi có ảnh hương tích cực đến ý định khởi nghiệp của sinh viên

\subsubsection{Giáo dục khởi nghiệp (Entrepreneurship education)}

Isaacs, Visser, Friedrich, và Brijlal (2007) định nghĩa "giáo dục khởi nghiệp” là sự can thiệp có mục đích của các nhà giáo dục trong việc truyền đạt những kiến thức cũng như kỹ năng cần thiết để người học có thể tồn tại được trong thế giới kinh doanh. Kuratko (2005) nhận định ý định khởi nghiệp sẽ trở nên mạnh mẽ hơn khi có sự tác động của hoạt động giảng dạy, đào tạo về khởi nghiệp tại trường đại học. Theo Turker và Selcuk (2009), nếu một trường đại học cung cấp đầy đủ kiến thức và nguồn cảm hứng cho sinh viên, đặc biệt là những kiến thức về khởi nghiệp thì ý định lựa chọn thực hiện khởi nghiệp sẽ tăng lên. Nghiên cứu của Wang và Wong (2004) cũng chỉ ra rằng giáo dục khởi nghiệp có sự ảnh hưởng tích cực đáng kể đến ý định tự kinh doanh. Từ những luận điểm này, nghiên cứu đề xuất giả thuyết H4 như sau: sinh viên

Giả thuyết H4: Giáo dục khởi nghiệp có ảnh hưởng tích cục đến ý định khởi nghiệp của

\subsubsection{Kinh nghiệm (Experience)}

Theo Obschonka, Silbereisen, và Schmitt-Rodermund (2010), kinh nghiệm trong nghiên cứu về khởi nghiệp được hiểu là những trải nghiệm trong việc làm của sinh viên (làm bán thời gian, hợp đồng...) có liên quan đến kinh doanh. T. T. Nguyen (2015) và Do (2016) bổ sung thêm kinh nghiệm còn là trải nghiệm với các vị trí quản lý mà sinh viên từng đảm nhiệm (chẳng hạn quản lý cấp lớp, cấp đoàn thể trong nhà trường, câu lạc bộ...). Như vậy, kinh nghiệm trong đề tài này sẽ được hiểu đồng thời theo quan điểm của các nghiên cứu trên. Devonish, Alleyne, CharlesSoverall, Young, Marshall, và Pounder (2010) đã đưa ra kết luận các kinh nghiệm liên quan đến kinh doanh, bán hàng của cá nhân có ảnh hưởng cùng chiều đến ý định khởi nghiệp của cá nhân đó sau này. Nghiên cứu của Suan và cộng sự (2011) tại Malaysia cho rằng kinh nghiệm của sinh viên có ảnh hưởng tích cực đến ý định khởi nghiệp. Rasli, Khan, Malekifar, và Jabeen (2013) cũng cho một kết quả nghiên cứu tương tự về tầm ảnh hưởng của kinh nghiệm đến ý định khởi nghiệp. Dựa trên những luận điểm này, nghiên cứu đề xuất giả thuyết H5 như sau: 
Giả thuyết H5: Kinh nghiệm có ảnh hưởng tích cực đến ý định khởi nghiệp của sinh viên

\subsection{6. Đặc điểm tính cách (Personality traits)}

Theo Nga và Shamuganathan (2010), đặc điểm tính cách của một cá nhân được định nghĩa là mô thức thường xuyên của hành vi, suy nghĩ hay cảm xúc. Đây là những đặc điểm bền vững, giải thích cho sự khác biệt của hành vi trong những tình huống tương tự nhau. Kickul và Gundry (2002) khi nghiên cứu về đặc điểm tính cách đã đo lường yếu tố này với các biến quan sát liên quan đến sự đối mặt và vượt qua trở ngại, giỏi xác định cơ hội và thích được thử thách với hiện trạng. Trong đề tài này, đặc điểm tính cách sẽ được đo lường theo hướng tính cách chủ động dựa trên quan điểm của Kickul và Gundry (2002). Nghiên cứu của Suan và cộng sự (2011) khẳng định rằng có một sự ảnh hưởng tích cực mạnh mẽ của đặc điểm tính cách lên ý định khởi nghiệp. Còn Karabulut (2016) cũng đưa ra mối quan hệ cùng chiều về tác động của đặc điểm tính cách cá nhân đối với ý định khởi nghiệp. Như vậy, dựa vào những luận điểm trên, nghiên cứu đề xuất giả thuyết H6 như sau: sinh viên

Giả thuyết H6: Đặc điểm tính cách có ảnh hưởng tích cực đến ý định khởi nghiệp của

\subsubsection{Nguồn vốn (Capital)}

Theo Mazzarol, Volery, Doss, và Thein (1999), nguồn vốn là một khía cạnh hay một đặc điểm kinh tế. Trong nghiên cứu ở đây, nguồn vốn được hiểu là tiền được sử dụng cho hoạt động khởi nghiệp. Nguồn vốn có thể đến từ sự hỗ trợ của gia đình, bạn bè, từ sự vay mượn, từ sự tiết kiệm của cá nhân hoặc các nguồn hỗ trợ khác. Nghiên cứu của Mazzarol và cộng sự (1999) cho rằng nguồn vốn sẵn có (nằm trong nhóm yếu tố môi trường kinh tế) tác động dương đến ý định khởi nghiệp. Zain và cộng sự (2010) đã xây dựng mô hình các yếu tố tác động đến ý định khởi nghiệp của sinh viên, trong đó có yếu tố về nguồn vốn, và kết quả thể hiện sự ảnh hưởng tích cực của nguồn vốn lên ý định khởi nghiệp. Từ những quan điểm trên, nghiên cứu đề xuất giả thuyết H7 như sau:

Giả thuyết H7: Nguồn vốn có ảnh hưởng tích cục đến ý định khởi nghiệp của sinh viên
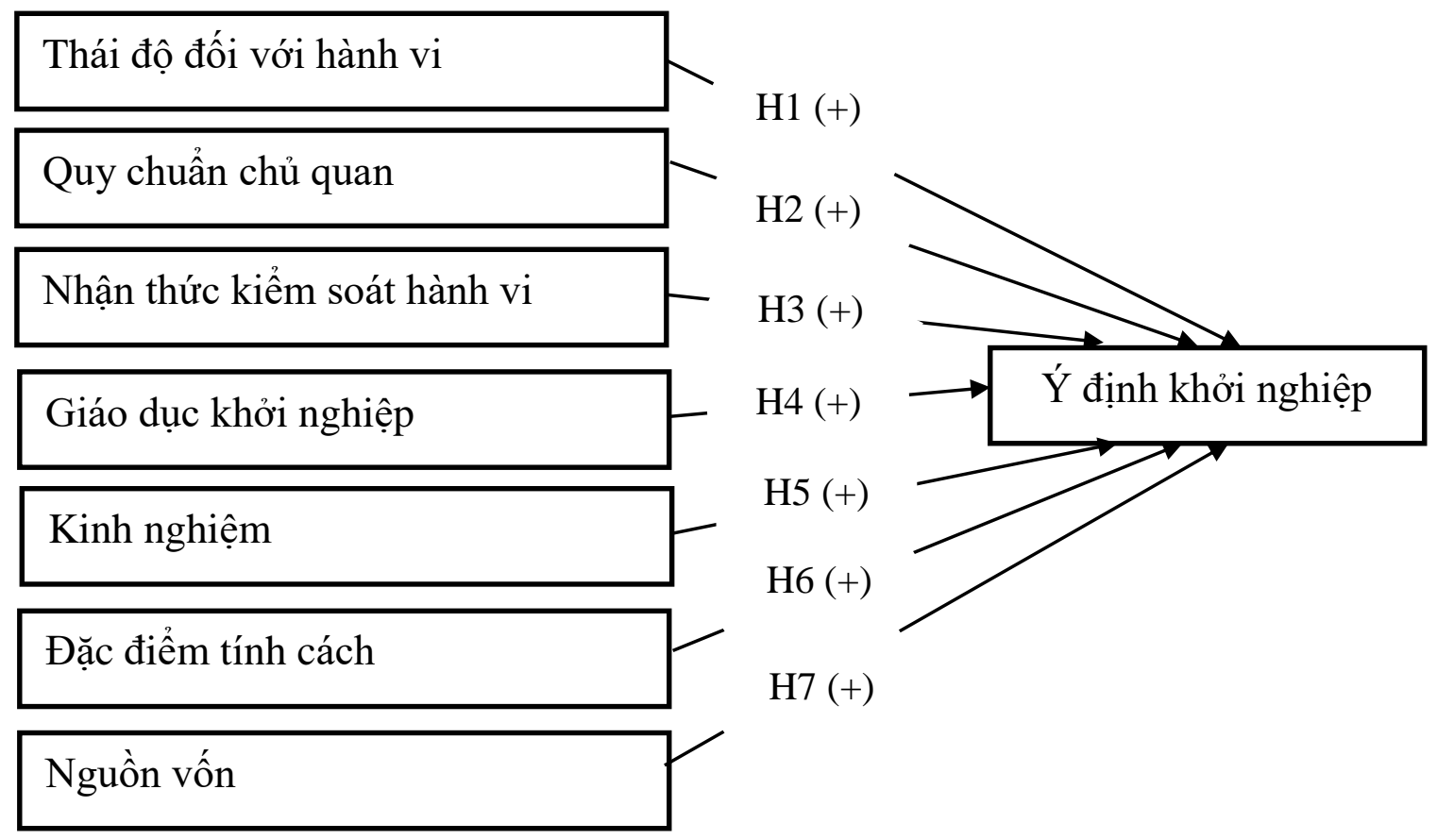

Hình 1. Mô hình nghiên cứu đề xuất 


\section{Phương pháp nghiên cứu}

Nghiên cứu sử dụng phương pháp nghiên cứu định tính và nghiên cứu định lượng.

\subsection{Nghiên cứu định tính}

Thực hiện thảo luận nhóm và thảo luận tay đôi. Trong đó, đối tượng thảo luận là các sinh viên năm cuối ngành Quản Trị Kinh Doanh (QTKD), các giảng viên thuộc bộ môn QTKD làm việc tại trường (thảo luận nhóm) và cựu sinh viên của trường đã khởi nghiệp thành công (thảo luận tay đôi). Trong mỗi buổi thảo luận, ý kiến của các thành viên tham gia đều được ghi nhận đầy đủ làm cơ sở cho việc hiệu chỉnh mô hình và thang đo các yếu tố ảnh hưởng đến ý định khởi nghiệp.

Kết quả nghiên cứu định tính thể hiện các thành viên tham gia thảo luận đều thống nhất bảy yếu tố ảnh hưởng đến ý định khởi nghiệp của sinh viên Trường Đại học Tiền Giang bao gồm: thái độ đối với hành vi, quy chuẩn chủ quan, nhận thức kiểm soát hành vi, giáo dục khởi nghiệp, kinh nghiệm, đặc điểm tính cách và nguồn vốn. Về thang đo, các thành viên tham gia thảo luận có góp ý điều chỉnh câu văn cho phù hợp; bổ sung ba biến trong mỗi thang đo của yếu tố quy chuẩn chủ quan, giáo dục khởi nghiệp và đặc điểm tính cách.

\subsection{Nghiên cúu định luọng}

\subsubsection{Tổng thể nghiên cưu}

Là tất cả các sinh viên năm cuối (năm ba cao đẳng và năm tư đại học) đang học tại Trường Đại học Tiền Giang. Theo số liệu thống kê từ phòng công tác sinh viên đến tháng $11 / 2019$, trường Đại học Tiền Giang có 1,035 sinh viên năm cuối. Lý do chọn đối tượng này vì đây là nhóm sinh viên đã có một thời gian dài học tập tại trường, đã được tiếp cận với kiến thức chuyên ngành cũng như hiểu biết rõ về các hoạt động của nhà trường. Ngoài ra, nhóm sinh viên này đang trong giai đoạn lựa chọn nghề nghiệp hoặc bắt đầu nghĩ đến những định hướng nghề nghiệp tương lai.

\subsubsection{Kich thước mẫu}

Theo T. D. Nguyen (2011), kích thước mẫu cần cho nghiên cứu định lượng phụ thuộc vào nhiều yếu tố như phương pháp xử lý dữ liệu (hồi quy, phân tích nhân tố khám phá EFA) hay độ tin cậy cần thiết.

T. D. Nguyen (2011) cho rằng để thực hiện phân tích nhân tố khám phá EFA, kích thước mẫu sẽ được tính bởi công thức $: \mathrm{n}=\mathrm{k}$ * số biến quan sát (trong đó, $\mathrm{k}$ là tỷ lệ quan sát/biến quan sát, $\mathrm{k}$ thường là $5 / 1$ ). Với số biến quan sát của mô hình nghiên cứu là 44 và hệ số $\mathrm{k}$ là $5 / 1$ thì kích thước mẫu tối thiểu cần cho nghiên cứu là 220 .

Cũng theo T. D. Nguyen (2011), để thực hiện phân tích hồi quy bội, kích thước mẫu thường được tính theo công thức: $\mathrm{n} \geq 50+8 \mathrm{k}$ (trong đó, $\mathrm{k}$ là số biến độc lập của mô hình). Với số biến độc lập của mô hình nghiên cứu là bảy thì kích thước mẫu tối thiểu cần cho nghiên cứu là 106.

Như vậy, xét các yêu cầu của phân tích EFA cũng như phân tích hồi quy bội, đồng thời xét giới hạn về mặt thời gian, số quan sát của nghiên cứu là 280 sẽ phù hợp.

\subsubsection{Chọn mẫu}

Nghiên cứu sử dụng phương pháp chọn mẫu phi xác suất với kỹ thuật chọn mẫu định mức bởi sự thuận tiện về mặt thời gian và chi phí, trong đó chọn mẫu định mức sẽ thực hiện phân nhóm tổng thể theo hai thuộc tính kiểm soát là bậc đào tạo (cao đẳng và đại học) và khoa 
quản lý ngành đào tạo, rồi thực hiện chọn mẫu thuận tiện (khảo sát đối tượng có thể tiếp cận được).

Cũng theo số liệu thống kê đến tháng 11/2019 của phòng công tác sinh viên, tỷ lệ sinh viên đại học là $58.76 \%$ và cao đẳng là $41.24 \%$. Các khoa quản lý ngành đào tạo gồm: các ngành thuộc khoa Kinh tế - Luật (KT-L), các ngành thuộc khoa Kỹ Thuật và Công Nghệ Thông Tin (KT \& CNTT), các ngành thuộc khoa Nông Nghiệp và Công Nghệ Thực Phẩm (NN \& CNTP), các ngành thuộc khoa Sư Phạm và Xã Hội Nhân Văn (SP \& XHNV), có tỷ lệ sinh viên lần lượt là $34.38 \%, 18.48 \%, 23.97 \%, 23.17 \%$. Như vậy, chọn mẫu định mức với 280 sinh viên phân bổ

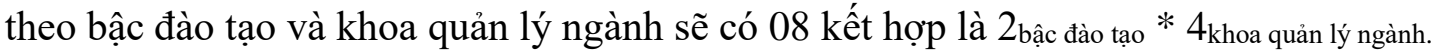

\section{Bảng 1}

Bảng chọn mẫu định mức theo bậc đào tạo và khoa quản lý ngành đào tạo

\begin{tabular}{|c|l|l|l|c|}
\hline Kết họ̣p & Bậc đào tạo & $\begin{array}{c}\text { Khoa quản lý } \\
\text { ngành đào tạo }\end{array}$ & Tỷ lệ trong mẫu (\%) & $\begin{array}{c}\text { Số phần tử } \\
\text { trong mẫu }\end{array}$ \\
\hline 1 & Đại học & KT -L & $58.76 \% * 34.38 \%=20.20 \%$ & 57 \\
\hline 2 & Đại học & KT \& CNTT & $58.76 \% * 18.48 \%=10.86 \%$ & 31 \\
\hline 3 & Đại học & NN \& CNTP & $58.76 \% * 23.97 \%=14.08 \%$ & 40 \\
\hline 4 & Đại học & SP \& XHNV & $58.76 \% * 23.17 \%=13.61 \%$ & 39 \\
\hline 5 & Cao đẳng & KT -L & $41.24 \% * 34.38 \%=14.18 \%$ & 38 \\
\hline 6 & Cao đẳng & KT \& CNTT & $41.24 \% * 18.48 \%=7.62 \%$ & 22 \\
\hline 7 & Cao đẳng & NN \& CNTP & $41.24 \% * 23.97 \%=9.89 \%$ & 27 \\
\hline 8 & Cao đẳng & SP \& XHNV & $41.24 \% * 23.17 \%=9.56 \%$ & 26 \\
\hline \multicolumn{5}{|l}{} \\
\hline
\end{tabular}

Nguồn: công thức tính toán T. D. Nguyen (2011)

\subsubsection{Thu thập dĩ liệu}

Dữ liệu được thu thập thông qua bảng câu hỏi khảo sát. Thang đo Likert 5 mức độ, trong đó $1=$ rất không đồng ý, $2=$ không đồng ý, $3=$ trung lập, $4=$ đồng ý và $5=$ rất đồng ý, được dùng để đo lường mức độ đồng ý của người được khảo sát cho từng phát biểu.

\subsubsection{Phân tích dũ liệu}

Dũ liệu sẽ được nhập, mã hoá, làm sạch và phân tích thông qua thống kê mô tả, kiểm định độ tin cậy thang đo Cronbach's Alpha, phân tích nhân tố khám phá EFA (Exploratory Factor Analysis) và hồi quy tuyến tính đa biến với sự hỗ trợ của phần mềm SPSS 22.0.

\section{Kết quả nghiên cứu và thảo luận}

\subsection{Kết quả nghiên cúu}

\subsubsection{Thống kê mô tả mẫu khảo sát}

Tổng số phiếu phát ra là 280 phiếu. Sau khi kiểm tra, có 10 phiếu không hợp lệ do đối tượng khảo sát không trả lời đầy đủ các thông tin trong bảng câu hỏi hoặc với cùng một phát biểu nhưng chọn nhiều mức độ khác nhau. Như vậy, số phiếu còn lại hợp lệ được dùng để đưa vào phân tích là 270 phiếu. 


\section{Bảng 2}

Thống kê mô tả mẫu khảo sát

\begin{tabular}{|c|c|c|c|}
\hline \multicolumn{2}{|l|}{ Chỉ tiêu thống kê } & $\begin{array}{l}\text { Số lưọng } \\
\text { sinh viên }\end{array}$ & Tỷ lệ (\%) \\
\hline \multirow{3}{*}{ Giới tính } & Nam & 129 & $47.78 \%$ \\
\hline & Nữ & 141 & $52.22 \%$ \\
\hline & Tổng cộng & 270 & $100.00 \%$ \\
\hline \multirow{3}{*}{ Bậc đào tạo } & Cao đẳng & 110 & $40.74 \%$ \\
\hline & Đại học & 160 & $59.26 \%$ \\
\hline & Tổng cộng & 270 & $100.00 \%$ \\
\hline \multirow{5}{*}{ Khoa quản lý ngành đào tạo } & $\mathrm{KT}-\mathrm{L}$ & 93 & $34.44 \%$ \\
\hline & KT \& CNTT & 51 & $18.90 \%$ \\
\hline & NN \& CNTP & 64 & $23.70 \%$ \\
\hline & SP \& XHNV & 62 & $22.96 \%$ \\
\hline & Tổng cộng & 270 & $100.00 \%$ \\
\hline \multirow{3}{*}{$\begin{array}{l}\text { Tình trạng tham gia các hoạt động } \\
\text { liên quan đến khởi nghiệp }\end{array}$} & Có & 131 & $48.52 \%$ \\
\hline & Không & 139 & $51.48 \%$ \\
\hline & Tổng công & 270 & $100.00 \%$ \\
\hline
\end{tabular}

Nguồn: Kết quả xử lý SPSS 22.0

\subsubsection{Thống kê mô tả thang đo}

\section{Bảng 3}

Thống kê mô tả các thang đo

\begin{tabular}{|l|l|c|c|}
\hline Mã biến & \multicolumn{1}{|c|}{ Nội dung biến quan sát } & Trung bình & Độ lệch chuẩn \\
\hline Thang đo “Thái độ đối với hành vi” & 0.835 \\
\hline TD1 & $\begin{array}{l}\text { Việc trở thành chủ doanh nghiệp đối với anh/chị có lợi } \\
\text { hơn bất lợi }\end{array}$ & 3.648 & 0.756 \\
\hline TD2 & $\begin{array}{l}\text { Chủ doanh nghiệp là một nghề rất hấp dẫn đối với } \\
\text { anh/chị }\end{array}$ & 3.911 & 0.802 \\
\hline TD3 & Anh/chị sẽ rất hài lòng khi làm chủ doanh nghiệp & 3.896 & 0.787 \\
\hline TD4 & $\begin{array}{l}\text { Trong số các lựa chọn công việc khác nhau, anh/chị } \\
\text { thích kinh doanh }\end{array}$ & 3.719 & \\
\hline Thang đo “Quy chuẩn chủ quan” & 3.930 & 0.789 \\
\hline QC1 & Gia đình luôn ủng hộ công việc của anh/chị & 3.915 & 0.744 \\
\hline QC2 & Bạn bè luôn ủng hộ công việc của anh/chị & 3.837 & 0.739 \\
\hline QC3 & Những người quan trọng khác đối với anh/chị luôn & \\
\hline
\end{tabular}




\begin{tabular}{|c|c|c|c|}
\hline Mã biến & Nội dung biến quan sát & Trung bình & Độ lệch chuẩn \\
\hline & ủng hộ công việc của anh/chị & & \\
\hline QC4 & Anh/chị biết nhiều doanh nhân thành công & 3.841 & 0.742 \\
\hline QC5 & Anh/chị rất ngưỡng mộ những doanh nhân thành công & 3.881 & 0.791 \\
\hline QC6 & $\begin{array}{l}\text { Anh/chị thường nghiên cứu các doanh nhân thành } \\
\text { công }\end{array}$ & 3.567 & 0.772 \\
\hline \multicolumn{4}{|c|}{ Thang đo "Nhận thức kiểm soát hành vi" } \\
\hline KS1 & Anh/chị nhận thấy thật dễ dàng để bắt đầu kinh doanh & 2.359 & 0.732 \\
\hline KS2 & Anh/chị biết cách để phát triển một dự án kinh doanh & 2.859 & 0.702 \\
\hline KS3 & $\begin{array}{l}\text { Anh/chị biết cụ thể những việc cần làm để tiến hành } \\
\text { kinh doanh }\end{array}$ & 2.944 & 0.762 \\
\hline KS4 & $\begin{array}{l}\text { Anh/chị có thể kiểm soát được quá trình hoạt động của } \\
\text { một doanh nghiệp mới }\end{array}$ & 2.930 & 0.731 \\
\hline KS5 & $\begin{array}{l}\text { Nếu anh/chị cố gắng, anh/chị sẽ thành công trong việc } \\
\text { kinh doanh }\end{array}$ & 3.756 & 0.761 \\
\hline \multicolumn{4}{|c|}{ Thang đo “Giáo dục khởi nghiệp” } \\
\hline GD1 & $\begin{array}{l}\text { Tại trường đại học, anh/chị được cung cấp những kiến } \\
\text { thức cần thiết về kinh doanh }\end{array}$ & 3.759 & 0.919 \\
\hline GD2 & $\begin{array}{l}\text { Tại trường đại học, anh/chị được cung cấp những kỹ } \\
\text { năng cần thiết về kinh doanh }\end{array}$ & 3.800 & 0.865 \\
\hline GD3 & $\begin{array}{l}\text { Tại trường đại học, anh/chị được khuyến khích phát } \\
\text { triển những ý tưởng kinh doanh sáng tạo }\end{array}$ & 3.815 & 0.898 \\
\hline GD4 & $\begin{array}{l}\text { Tại trường đại học, anh/chị được khuyến khích tham } \\
\text { gia cuộc thi "Sinh viên khởi nghiệp" }\end{array}$ & 3.841 & 0.945 \\
\hline GD5 & $\begin{array}{l}\text { Tại trường đại học, anh/chị được khuyến khích tham } \\
\text { gia các lớp tập huân "Khởi sự kinh doanh" }\end{array}$ & 3.781 & 0.900 \\
\hline GD6 & Anh/chị thường tự học để có kiến thức kinh doanh & 3.652 & 0.947 \\
\hline \multicolumn{4}{|c|}{ Thang đo “Kinh nghiệm” } \\
\hline KN1 & $\begin{array}{l}\text { Anh/chị đã từng làm công việc liên quan đến kinh } \\
\text { doanh }\end{array}$ & 3.463 & 1.033 \\
\hline $\mathrm{KN} 2$ & $\begin{array}{l}\text { Anh/chị đã từng tham gia công tác quản lý (cán bộ } \\
\text { lớp, cán bộ Đoàn,...) }\end{array}$ & 3.333 & 1.144 \\
\hline KN3 & $\begin{array}{l}\text { Anh/chị đã từng là thành viên của câu lạc bộ kinh } \\
\text { doanh trong hoặc ngoài nhà trường }\end{array}$ & 2.722 & 0.953 \\
\hline KN4 & $\begin{array}{l}\text { Anh/chị đã từng tham gia các hoạt động ngoại khóa tại } \\
\text { các doanh nghiệp }\end{array}$ & 3.026 & 0.981 \\
\hline KN5 & $\begin{array}{l}\text { Anh/chị đã từng tham gia các buổi hội thảo về kinh } \\
\text { doanh }\end{array}$ & 3.459 & 0.962 \\
\hline
\end{tabular}




\begin{tabular}{|c|c|c|c|}
\hline Mã biến & Nội dung biến quan sát & Trung bình & Độ lệch chuẩn \\
\hline \multicolumn{4}{|c|}{ Thang đo “Đặc điểm tính cách" } \\
\hline TC1 & Anh/chị là người dám đối mặt với trở ngại & 3.752 & 0.758 \\
\hline TC2 & Anh/chị là người dám vượt qua mọi trở ngại & 3.696 & 0.754 \\
\hline TC3 & $\begin{array}{l}\text { Anh/chị là người rất giỏi trong việc xác định các cơ } \\
\text { hội }\end{array}$ & 3.044 & 0.655 \\
\hline TC4 & $\begin{array}{l}\text { Anh/chị là người thích được thử thách với những } \\
\text { nhiệm vụ khó khăn }\end{array}$ & 3.619 & 0.705 \\
\hline TC5 & Anh/chị là người dám chấp nhận rủi ro & 3.511 & 0.750 \\
\hline TC6 & Anh/chị là người có tính sáng tạo & 3.656 & 0.729 \\
\hline TC7 & Anh/chị là người thích tự lập & 3.604 & 0.773 \\
\hline \multicolumn{4}{|c|}{ Thang đo "Nguồn vốn" } \\
\hline NV1 & Anh/chị có thể vay, mượn tiền từ gia đình và bạn bè & 3.685 & 0.991 \\
\hline NV2 & $\begin{array}{l}\text { Anh/chị có thể vay tiền từ các tổ chức tài chính (như } \\
\text { ngân hàng, quỹ tín dụng) }\end{array}$ & 3.815 & 0.898 \\
\hline NV3 & $\begin{array}{l}\text { Anh/chị có thể tích lũy vốn từ việc làm thêm hoặc tiết } \\
\text { kiệm }\end{array}$ & 3.652 & 0.852 \\
\hline NV4 & $\begin{array}{l}\text { Địa phương anh/chị có các chính sách hỗ trợ vốn cho } \\
\text { thanh niên }\end{array}$ & 3.796 & 0.900 \\
\hline NV5 & Anh/chị dễ dàng tiếp cận các nguồn vốn & 3.678 & 0.769 \\
\hline \multicolumn{4}{|c|}{ Thang đo "Ý định khởi nghiệp" } \\
\hline YD1 & $\begin{array}{l}\text { Mục tiêu nghề nghiệp của anh/chị là khởi sự kinh } \\
\text { doanh }\end{array}$ & 3.452 & 0.778 \\
\hline YD2 & $\begin{array}{l}\text { Anh/chị có mong muốn mạnh mẽ để khởi sự kinh } \\
\text { doanh trong tương lai }\end{array}$ & 3.507 & 0.826 \\
\hline YD3 & $\begin{array}{l}\text { Anh/chị muốn là người chủ doanh nghiệp hơn là nhân } \\
\text { viên }\end{array}$ & 3.593 & 0.843 \\
\hline YD4 & $\begin{array}{l}\text { Anh/chị có sự suy nghĩ nghiêm túc về việc khởi sự } \\
\text { kinh doanh sau này }\end{array}$ & 3.681 & 0.777 \\
\hline YD5 & $\begin{array}{l}\text { Anh/chị sẵn sàng làm mọi việc cần thiết để khởi sự } \\
\text { kinh doanh }\end{array}$ & 3.537 & 0.793 \\
\hline YD6 & Nếu có cơ hội, anh/chị sẽ khởi sự kinh doanh & 3.548 & 0.838 \\
\hline
\end{tabular}

Nguồn: Kết quả xử lý SPSS 22.0

\subsubsection{Kiểm định độ tin cậy của thang đo qua hệ số Cronbach's Alpha}

Theo T. D. Nguyen (2011), một thang đo có thể chấp nhận được về mặt độ tin cậy nếu Cronbach Alpha $\geq 0.6$ và hệ số tương quan biến - tổng của biến quan sát lớn hơn 0.4. Về lý thuyết, hệ số Cronbach's Alpha càng lớn thì thang đo có độ tin cậy càng cao. Tuy nhiên, nếu hệ số này quá lớn $(>0.95)$ thì lại cho thấy nhiều biến trong thang đo không có khác biệt nhau. Còn 
theo Hoang và Chu (2008), nếu hệ số Cronbach Alpha từ 0.6 trở lên là có thể sử dụng được. Vậy, để kiểm định chất lượng thang đo, nghiên cứu sử dụng Cronbach's Alpha $\geq 0.6$ và hệ số tương quan biến - tổng $>0.4$.

Nghiên cứu đã tiến hành thực hiện phân tích độ tin cậy của thang đo 02 lần. Sau khi thực hiện phân tích độ tin cậy thang đo lần 01 , các biến quan sát QC6, KS5, KN5, TC3, TC6 và NV5 đều bị loại do có hệ số tương quan biến - tổng nhỏ hơn 0.4. Sau thực hiện phân tích độ tin cậy thang đo lần 02 , các thang đo đều đạt yêu cầu về độ tin cậy để tiếp tục thực hiện phân tích nhân tố khám phá EFA.

\section{Bảng 4}

Bảng Cronbach's Alpha thang đo các biến (lần 02)

\begin{tabular}{|c|c|c|c|}
\hline Mã biến & $\begin{array}{c}\text { Trung bình thang đo } \\
\text { nếu loại biến }\end{array}$ & $\begin{array}{l}\text { Hệ số tương quan } \\
\text { biến-tổng }\end{array}$ & $\begin{array}{l}\text { Hệ số Cronbach's } \\
\text { Alpha nếu loại biến }\end{array}$ \\
\hline \multicolumn{4}{|c|}{ Thang đo "Thái độ đối với hành vi” - Hệ số Cronbach's Alpha: 0.788} \\
\hline TD1 & 11.526 & 0.591 & 0.730 \\
\hline TD2 & 11.263 & 0.595 & 0.728 \\
\hline TD3 & 11.278 & 0.586 & 0.732 \\
\hline TD4 & 11.456 & 0.586 & 0.732 \\
\hline \multicolumn{4}{|c|}{ Thang đo “Quy chuẩn chủ quan” - Hệ số Cronbach's Alpha: 0.905} \\
\hline QC1 & 15.474 & 6.503 & 0.838 \\
\hline QC2 & 15.489 & 7.136 & 0.707 \\
\hline QC3 & 15.567 & 7.228 & 0.687 \\
\hline QC4 & 15.563 & 6.901 & 0.782 \\
\hline QC5 & 15.522 & 6.637 & 0.795 \\
\hline \multicolumn{4}{|c|}{ Thang đo "Nhận thức kiểm soát hành vi” - Hệ số Cronbach's Alpha: 0.781} \\
\hline KS1 & 8.733 & 3.445 & 0.440 \\
\hline KS2 & 8.233 & 3.109 & 0.636 \\
\hline KS3 & 8.148 & 2.840 & 0.684 \\
\hline KS4 & 8.163 & 3.103 & 0.598 \\
\hline \multicolumn{4}{|c|}{ Thang đo "Giáo dục khởi nghiệp” - Hệ số Cronbach's Alpha: 0.910 } \\
\hline GD1 & 18.889 & 0.855 & 0.878 \\
\hline GD2 & 18.848 & 0.699 & 0.901 \\
\hline GD3 & 18.833 & 0.753 & 0.893 \\
\hline GD4 & 18.807 & 0.739 & 0.895 \\
\hline GD5 & 18.867 & 0.630 & 0.910 \\
\hline GD6 & 18.996 & 0.820 & 0.883 \\
\hline
\end{tabular}




\begin{tabular}{|c|c|c|c|}
\hline Mã biến & $\begin{array}{c}\text { Trung bình thang đo } \\
\text { nếu loại biến }\end{array}$ & $\begin{array}{l}\text { Hệ số tương quan } \\
\text { biến-tổng }\end{array}$ & $\begin{array}{l}\text { Hệ số Cronbach's } \\
\text { Alpha nếu loại biến }\end{array}$ \\
\hline \multicolumn{4}{|c|}{ Thang đo “Kinh nghiệm” - Hệ số Cronbach's Alpha: 0.674} \\
\hline KN1 & 9.081 & 5.547 & 0.406 \\
\hline $\mathrm{KN} 2$ & 9.211 & 4.844 & 0.484 \\
\hline KN3 & 9.822 & 5.292 & 0.546 \\
\hline KN4 & 9.519 & 5.745 & 0.401 \\
\hline \multicolumn{4}{|c|}{ Thang đo "Đặc điểm tính cách" - Hệ số Cronbach's Alpha: 0.891 } \\
\hline $\mathrm{TC} 1$ & 14.430 & 6.268 & 0.764 \\
\hline TC2 & 14.485 & 6.258 & 0.772 \\
\hline TC4 & 14.563 & 6.894 & 0.635 \\
\hline TC5 & 14.670 & 6.341 & 0.751 \\
\hline TC7 & 14.578 & 6.260 & 0.746 \\
\hline \multicolumn{4}{|c|}{ Thang đo “Nguồn vốn” - Hệ số Cronbach's Alpha: 0.828} \\
\hline NV1 & 11.263 & 4.849 & 0.675 \\
\hline $\mathrm{NV} 2$ & 11.133 & 5.320 & 0.640 \\
\hline NV3 & 11.296 & 5.473 & 0.647 \\
\hline NV4 & 11.152 & 5.237 & 0.663 \\
\hline \multicolumn{4}{|c|}{ Thang đo "Ý định khởi nghiệp" - Hệ số Cronbach's Alpha: 0.828 } \\
\hline YD1 & 17.867 & 0.550 & 0.810 \\
\hline YD2 & 17.811 & 0.490 & 0.823 \\
\hline YD3 & 17.726 & 0.729 & 0.772 \\
\hline YD4 & 17.637 & 0.513 & 0.818 \\
\hline YD5 & 17.781 & 0.587 & 0.803 \\
\hline YD6 & 17.770 & 0.724 & 0.773 \\
\hline
\end{tabular}

Nguồn: Kết quả xử lý SPSS 22.0

\subsubsection{Phân tích nhân tố khám phá-EFA}

a. Phân tích EFA các biến độc lập

Hệ số $\mathrm{KMO}=0.764>0.5$, đồng thời căn cứ vào kiểm định Bartlett với Sig. $=0.00<0.05$ (mức ý nghĩa $5 \%$ ), các biến quan sát có tương quan với nhau. Đại lượng Eigenvalue của nhân tố thứ 07 là $1.243>1$, nghiên cứu xác định có bảy nhân tố được trích ra từ dữ liệu khảo sát với tổng phương sai trích (cumulative \%) là $68.925 \%>50 \%$.

Ma trận xoay nhân tố (Rolated Component Matrix) với phép xoay Varimax xác định cụ thể bảy nhóm nhân tố như sau: 


\section{Bảng 5}

Bảng ma trận xoay nhân tố các biến độc lập (EFA lần 02)

\begin{tabular}{|c|c|c|c|c|c|c|c|}
\hline & \multicolumn{7}{|c|}{ Nhân tố } \\
\hline & 1 & 2 & 3 & 4 & 5 & 6 & 7 \\
\hline GD1 & 0.904 & & & & & & \\
\hline GD6 & 0.882 & & & & & & \\
\hline GD3 & 0.828 & & & & & & \\
\hline GD4 & 0.823 & & & & & & \\
\hline GD2 & 0.795 & & & & & & \\
\hline GD5 & 0.736 & & & & & & \\
\hline $\mathrm{QC1}$ & & 0.908 & & & & & \\
\hline QC5 & & 0.885 & & & & & \\
\hline QC4 & & 0.830 & & & & & \\
\hline QC2 & & 0.753 & & & & & \\
\hline QC3 & & 0.701 & & & & & \\
\hline TC2 & & & 0.881 & & & & \\
\hline TC1 & & & 0.872 & & & & \\
\hline TC5 & & & 0.701 & & & & \\
\hline TC4 & & & 0.686 & & & & \\
\hline TC7 & & & 0.678 & & & & \\
\hline NV4 & & & & 0.826 & & & \\
\hline NV1 & & & & 0.824 & & & \\
\hline NV3 & & & & 0.798 & & & \\
\hline NV2 & & & & 0.797 & & & \\
\hline TD3 & & & & & 0.756 & & \\
\hline TD4 & & & & & 0.729 & & \\
\hline TD2 & & & & & 0.712 & & \\
\hline TD1 & & & & & 0.683 & & \\
\hline KS3 & & & & & & 0.855 & \\
\hline KS2 & & & & & & 0.838 & \\
\hline KS4 & & & & & & 0.755 & \\
\hline $\mathrm{KN} 2$ & & & & & & & 0.802 \\
\hline KN3 & & & & & & & 0.694 \\
\hline KN1 & & & & & & & 0.678 \\
\hline
\end{tabular}

Nguồn: Kết quả xử lý SPSS 22.0 
- Nhân tố 1: bao gồm các biến quan sát GD1, GD2, GD3, GD4, GD5, GD6. Nhân tố này được đặt tên là "Giáo dục khởi nghiệp" (ký hiệu GD).

- Nhân tố 2: bao gồm các biến quan sát QC1, QC2, QC3, QC4, QC5. Nhân tố này được đặt tên là "Quy chuẩn chủ quan” (ký hiệu QC).

- Nhân tố 3: bao gồm các biến quan sát TC1, TC2, TC4, TC5, TC7. Nhân tố này được đặt tên là "Đặc điểm tính cách" (ký hiệu TC).

- Nhân tố 4: bao gồm các biến quan sát NV1, NV2, NV3, NV4. Nhân tố này được đặt tên là "Nguồn vốn" (ký hiệu NV).

- Nhân tố 5: bao gồm các biến quan sát TD1, TD2, TD3, TD4. Nhân tố này được đặt tên là “Thái độ đối với hành vi” (ký hiệu TD).

- Nhân tố 6: bao gồm các biến quan sát $\mathrm{KS} 2, \mathrm{KS} 3, \mathrm{KS} 4$. Nhân tố này được đặt tên là "Nhận thức kiểm soát hành vi" (ký hiệu KS).

- Nhân tố 7: bao gồm các biến quan sát KN1, KN2, KN3. Nhân tố này được đặt tên là "Kinh nghiệm" (ký hiệu KN).

\section{b. Phân tích EFA biến phụ thuộc}

Hệ số $\mathrm{KMO}=0.730>0.5$, kiểm định Bartlett với Sig. $=0.000<0.05$ (mức ý nghĩa 5\%), các biến quan sát có tương quan với nhau trong tổng thể.

Đại lượng Eigenvalue của nhân tố thứ nhất là $3.255>1$ cho thấy sự hội tụ của phép phân tích dừng ở nhân tố thứ nhất, tổng phương sai trích (cumulative \%) là $54.254 \%>50 \%$, hệ số tải nhân tố đều lớn hơn 0.5 . Như vậy, kết quả phân tích EFA biến phụ thuộc thể hiện có một nhân tố được rút trích từ sáu biến quan sát của thang do ý định khởi nghiệp, và nhân tố này giải thích đến $54.254 \%$ sự biến thiên của bộ dữ liệu.

Từ kiểm định $\mathrm{KMO}$ và Bartlett, phân tích EFA trong nghiên cứu này là phù hợp.

\section{Phân tích hồi quy tuyến tính đa biến}

Phân tích tương quan

\section{Bảng 6}

Ma trận hệ số tương quan Pearson

\begin{tabular}{lcccccccc}
\hline & YD & TD & QC & KS & GD & KN & TC & NV \\
\hline YD & 1.000 & & & & & & & \\
TD & $0.393^{* *}$ & 1.000 & & & & & & \\
QC & $0.378^{* *}$ & $0.451^{* *}$ & 1.000 & & & & & \\
KS & $0.394^{* *}$ & $0.209^{* *}$ & 0.110 & 1.000 & & & & \\
GD & $0.255^{* *}$ & -0.001 & -0.032 & -0.084 & 1.000 & & & \\
KN & $0.501^{* *}$ & $0.185^{* *}$ & $0.186^{* *}$ & 0.314 & 0.038 & 1.000 & & \\
TC & $0.582^{* *}$ & $0.520^{* *}$ & $0.414^{* *}$ & 0.287 & -0.015 & $0.351^{* *}$ & 1.000 & \\
NV & 0.024 & 0.020 & -0.068 & -0.015 & 0.074 & -0.010 & 0.034 & 1.000 \\
\hline
\end{tabular}

Nguồn: Kết quả xử lý SPSS 22.0 
Theo kết quả từ Bảng 6 , các biến độc lập đều có tương quan với biến phụ thuộc, còn hệ số tương quan giữa các biến độc lập là rất thấp nên không phát hiện hiện tượng đa cộng tuyến. Tuy nhiên, việc kiểm tra đa cộng tuyến khi phân tích hồi quy vẫn được thực hiện để đảm bảo độ tin cậy cho kết quả nghiên cứu.

Kiểm định sự phù hợp của mô hình

\section{Bảng 7}

Bảng tóm tắt mô hình

\begin{tabular}{|c|c|c|c|c|c|c|c|c|c|}
\hline \multirow[b]{2}{*}{$\mathrm{R}$} & \multirow[b]{2}{*}{$\mathrm{R}^{2}$} & \multirow{2}{*}{$\begin{array}{l}\mathrm{R}^{2} \text { hiệu } \\
\text { chỉnh }\end{array}$} & \multirow{2}{*}{$\begin{array}{l}\text { Sai số } \\
\text { chuẩn ước } \\
\text { lượng }\end{array}$} & \multicolumn{5}{|c|}{ Thống kê thay đổi } & \multirow{2}{*}{$\begin{array}{l}\text { Durbin } \\
\text { Watson }\end{array}$} \\
\hline & & & & $\begin{array}{c}\mathrm{R}^{2} \text { thay } \\
\text { đồi }\end{array}$ & $\begin{array}{c}\text { F thay } \\
\text { đồi }\end{array}$ & df1 & $\mathrm{df} 2$ & $\begin{array}{l}\text { Sig. F thay } \\
\text { đổi }\end{array}$ & \\
\hline $.750^{\mathrm{a}}$ & 0.563 & 0.551 & 0.398 & 0.563 & 48.136 & 7 & 262 & 0.000 & 1.806 \\
\hline
\end{tabular}

Nguồn: Kết quả xử lý SPSS 22.0

$\mathrm{R}^{2}$ hiệu chỉnh $=0.551$, có nghĩa là mô hình hồi quy tuyến tính đa biến đã xây dựng phù hợp với tập dữ liệu đến $55.1 \%$. Ngoài ra, giá trị Sig. $=0.000<0.05$ (mức ý nghĩa $5 \%$ ), cho thấy mô hình có ý nghĩa thống kê chung với bảy biến độc lập.

\section{Phưong trình hồi quy tuyến tính đa biến}

\section{Bảng 8}

Bảng hệ số hồi quy

\begin{tabular}{|l|c|c|c|c|c|c|c|}
\hline \multirow{2}{*}{} & \multicolumn{2}{|c|}{$\begin{array}{c}\text { Hệ số } \\
\text { chưa chuẩn hóa }\end{array}$} & $\begin{array}{c}\text { Hệ̉ số } \\
\text { chuấn hóa }\end{array}$ & \multirow{2}{*}{ T } & \multirow{2}{*}{ Sig. } & \multicolumn{2}{c|}{$\begin{array}{c}\text { Thống kê hiện } \\
\text { tưộng cộng tuyến }\end{array}$} \\
\cline { 2 - 4 } & B & Sai số chuẩn & Beta & & & Dung sai & VIF \\
\hline (Hằng số) & -0.397 & 0.266 & & -1.494 & 0.136 & & \\
\hline TD & $\mathbf{0 . 0 5 4}$ & 0.048 & 0.056 & 1.117 & $\mathbf{0 . 2 6 5}$ & 0.657 & 1.522 \\
\hline QC & 0.135 & 0.043 & 0.147 & 3.101 & 0.002 & 0.741 & 1.349 \\
\hline KS & 0.199 & 0.043 & 0.207 & 4.676 & 0.000 & 0.850 & 1.177 \\
\hline GD & 0.213 & 0.032 & 0.272 & 6.602 & 0.000 & 0.982 & 1.019 \\
\hline KN & 0.198 & 0.034 & 0.267 & 5.914 & 0.000 & 0.819 & 1.220 \\
\hline TC & 0.326 & 0.049 & 0.343 & 6.596 & 0.000 & 0.618 & 1.619 \\
\hline NV & $\mathbf{0 . 0 0 6}$ & 0.033 & 0.007 & 0.169 & $\mathbf{0 . 8 6 6}$ & 0.984 & 1.016 \\
\hline
\end{tabular}

Nguồn: Kết quả xử lý SPSS 22.0

Theo kết quả từ Bảng 8, "Nguồn Vốn" (NV) và "Thái Độ đối với hành vi” (TD) không có ý nghĩa thống kê với giá trị Sig. lần lượt là $=0.866$ và $0.265>0.05$ (mức ý nghĩa $5 \%$ ), giả thuyết H1 và $\mathrm{H} 7$ không được chấp nhận. Các biến độc lập còn lại đều có ý nghĩa thống kê do có giá trị Sig. $=0.000<0.05$ nên chấp nhận các giả thuyết $\mathrm{H} 2, \mathrm{H} 3, \mathrm{H} 4, \mathrm{H} 5$ và $\mathrm{H} 6$.

\section{Kiểm định các giả định cần thiết trong hồi quy tuyến tính}

Phân phối của phần dư xấp xỉ chuẩn với Mean (trung bình) $=0$ và Std. Dev (độ lệch 
chuẩn $)=0.986$ (gần bằng 1). Như vậy, giả định phân phối chuẩn của phần dư không bị vi phạm.

Theo Hoang và Chu (2008), đại lượng Durbin-Watson (d) có giá trị biến thiên trong khoảng từ 0 đến 4 . Nếu các phần dư không có tương quan chuỗi bậc nhất với nhau, giá trị $\mathrm{d}$ sẽ gần bằng 2 . Theo Bảng 7 , đại lượng Durbin-Watson của mô hình hồi quy là 1.804 . Như vậy, giả định về tính độc lập của sai số không bị vi phạm.

VIF của mỗi biến độc lập đều nhỏ hơn 10. Như vậy, giả định không có mối tương quan giữa các biến độc lập không bị vi phạm, hay không có dấu hiệu đa cộng tuyến.

\section{Kiểm định sụ khác biệt về ý định khởi nghiệp của sinh viên}

Theo giới tính: Kiểm định Levene có giá trị Sig. $=0.128>0.05$, trong kiểm định $\mathrm{T}$ (T-test), giá trị Sig. $=0.000<0.05$ (mức ý nghĩa $5 \%$ ). Như vậy ý định khởi nghiệp giữa nam sinh viên và nữ sinh viên là khác nhau, trong đó sinh viên nam có ý định khởi nghiệp cao hơn sinh viên nữ.

Theo bậc đào tạo: Kiểm định Levene có giá trị Sig. $=0.391>0.05$, trong kiểm định $\mathrm{T}$ (T-test), giá trị Sig. $=0.267>0.05$ (mức ý nghĩa 5\%) nên không có sự khác biệt về ý định khởi nghiệp của sinh viên bậc cao đẳng và sinh viên bậc đại học tại trường.

Theo tình trạng tham gia các hoạt động liên quan đến khởi nghiệp: Kiểm định Levene có giá trị Sig. $=0,981>0.05$, trong kiểm định $\mathrm{T}(\mathrm{T}$-test), giá trị Sig. $=0.072>0.05$ (mức ý nghĩa $5 \%$ ) nên không có sự khác biệt về ý định khởi nghiệp giữa những sinh viên có tham gia và không có tham gia các hoạt động liên quan khởi nghiệp.

\subsection{Thảo luận}

Kết quả nghiên cứu cho thấy có năm nhân tố ảnh hưởng tích cực đến ý định khởi nghiệp của sinh viên tại Trường Đại học Tiền Giang, được sắp xếp theo mức độ ảnh hưởng giảm dần bao gồm: đặc điểm tính cách $(\beta=0.343)$, giáo dục khởi nghiệp $(\beta=0.272)$, kinh nghiệm $(\beta=$ $0.267)$, nhận thức kiểm soát hành vi $(\beta=0.207)$ và quy chuẩn chủ quan $(\beta=0.147)$. Không giống nhiều nghiên cứu trước (Ambad \& Damit, 2016; Hoang \& Bui, 2013; Phan \& Giang, 2015; Sabah, 2016), nghiên cứu này kết luận "nguồn vốn” và "thái độ đối với hành vi” không có ý nghĩa thống kê.

\subsection{1. Đối với đặc điểm tính cách}

Đây là nhân tố có mức độ tác động mạnh nhất so với các nhân tố còn lại $(\beta=0.343)$. Nhân tố này trong nghiên cứu được xem xét trên phương diện của tính cách chủ động, rất cần có ở người muốn khởi nghiệp kinh doanh. Kết quả phân tích hồi quy bội thể hiện đặc điểm tính cách có ảnh hưởng tích cực đến ý định khởi nghiệp và giả thuyết $\mathrm{H} 7$ được chấp nhận. Nếu sinh viên của trường được trau dồi, rèn luyện để hình thành những đặc điểm tính cách chủ động như bản lĩnh dám đối mặt với trở ngại, tính tự lập, dám chấp nhận rủi ro, ... thì ý định khởi nghiệp của sinh viên càng trở nên mạnh mẽ. Kết quả này tương đồng với nghiên cứu trước đây của Suan và cộng sự (2011) hay nghiên cứu của Hoang và Bui (2013).

\subsection{2. Đối với giáo dục khởi nghiệp}

Đây là nhân tố có mức độ tác động mạnh thứ hai $(\beta=0.272)$. Kết quả phân tích hồi quy bội thể hiện giáo dục khởi nghiệp có ảnh hưởng tích cực đến ý định khởi nghiệp và giả thuyết $\mathrm{H} 4$ được chấp nhận. Điều này có nghĩa, nếu sinh viên càng nhận được nhiều sự giáo dục về khởi nghiệp tại trường đại học thì ý định khởi nghiệp của sinh viên cũng sẽ tăng lên. Kết quả này phù hợp với nghiên cứu trước đây của Suan và cộng sự (2011) hay Zhang và cộng sự (2014). Thực tế trong thời gian qua, nhà trường luôn quan tâm đến việc phát triển những ý tưởng kinh doanh 
sáng tạo trong sinh viên thông qua cuộc thi "Sinh viên khởi nghiệp" hay các lớp học ngắn hạn về lập kế hoạch kinh doanh. Giáo dục khởi nghiệp tại trường không chỉ trang bị kiến thức, kỹ năng kinh doanh cho sinh viên mà còn định hướng thái độ đúng đắn đối với khởi nghiệp.

\subsection{3. Đối với kinh nghiệm}

Đây là nhân tố có mức độ tác động mạnh thứ ba $(\beta=0.267)$. Kết quả phân tích hồi quy bội thể hiện kinh nghiệm có ảnh hưởng tích cực đến ý định khởi nghiệp và giả thuyết $\mathrm{H} 5$ được chấp nhận. Như vậy, những sinh viên nào đã từng trải nghiệm với các hoạt động kinh doanh, bán hàng hoặc quản lý lớp, câu lạc bộ, ... tại trường đại học thì ý định khởi nghiệp của sinh viên đó sẽ càng mạnh mẽ. Kết quả này cũng phù hợp với nghiên cứu của Suan và cộng sự (2011) hay Do (2016). Sự trải nghiệm đối với các hoạt động kinh doanh thực tiễn hay tham gia các chương trình thực tập sinh tại các công ty, doanh nghiệp... là rất quan trọng để giúp sinh viên biết được mình cần phải làm những gì khi lựa chọn con đường khởi nghiệp kinh doanh sau này.

\subsection{4. Đối với nhận thức kiểm soát hành vi}

Đây là nhân tố có mức độ tác động mạnh thứ tư $(\beta=0.207)$. Kết quả phân tích hồi quy bội thể hiện nhận thức kiểm soát hành vi có ảnh hưởng tích cực đến ý định khởi nghiệp và giả thuyết $\mathrm{H} 3$ được chấp nhận. Điều này có nghĩa, nếu nhận thức kiểm soát hành vi của sinh viên tăng thì ý định khởi nghiệp của sinh viên cũng tăng theo. Kết quả này tương đồng với nghiên cứu trước đó của Ambad và Damit (2016), Sabah (2016) hay Phan và Giang (2015). Tuy nhiên, mức độ ảnh hưởng của nhận thức kiểm soát hành vi trong nghiên cứu này không được mạnh mẽ so với các nghiên cứu trước đó. Ngoài ra, nhiều sinh viên chưa biết cách phát triển một dự án kinh doanh thực tế cũng như cách thức kiểm soát quá trình hoạt động của một doanh nghiệp mới nên sự đánh giá của sinh viên nhà trường đối với nhân tố này không cao (trung bình đánh giá thang đo của nhân tố này là 2.970 , thấp nhất trong các thang đo).

\subsection{5. Đối với quy chuẩn chủ quan}

Kết quả phân tích hồi quy bội thể hiện quy chuẩn chủ quan có ảnh hưởng tích cực đến ý định khởi nghiệp và giả thuyết $\mathrm{H} 2$ được chấp nhận. Điều này có nghĩa, nếu sinh viên nhận được nhiều sự ủng hộ từ gia đình, người thân, bạn bè hay những người quan trọng khác thì ý định khởi nghiệp của sinh viện cũng sẽ tăng lên. Đây là nhân tố có mức độ tác động yếu nhất trong các nhân tố $(\beta=0.147)$. Kết quả này tương đồng với nghiên cứu của Ambad và Damit (2016), Sabah (2016), hay nghiên cứu của Phan và Giang (2015). Xét một đất nước với nền văn hóa Á Đông như Việt Nam thì suy nghĩ và hành động của cá nhân thường chịu tác động bởi ý kiến của những người xung quanh. Đặc biệt, sinh viên phần lớn là những người đã có thời gian dài sống với gia đình, phụ thuộc vào gia đình thì ý kiến cũng như quan điểm của gia đình có sự ảnh hưởng nhất định đến ý định khởi nghiệp của sinh viên sau này.

\subsubsection{Hạn chế của nghiên cứu và đề xuất hướng nghiên cứu tiếp theo}

Nghiên cứu chỉ thực hiện khảo sát trên đối tượng là sinh viên năm cuối mà bỏ qua các đối tượng sinh viên năm nhất hay năm hai, năm ba. Các nghiên cứu trong tương lai cần mở rộng khảo sát thêm trên các đối tượng sinh viên này để có sự so sánh, đánh giá khách quan hơn về ý định khởi nghiệp. Bên cạnh đó, các biến độc lập trong mô hình nghiên cứu chỉ giải thích được $55.1 \%$ sự biến thiên của biến phụ thuộc. Điều này có nghĩa mặc dù mô hình nghiên cứu là phù hợp nhưng vẫn còn $44.9 \%$ thuộc về các nhân tố khác chưa được đề cập trong mô hình, chẳng hạn như chính sách địa phương. Các nghiên cứu tiếp theo cần xem xét thêm các nhân tố ảnh hưởng sao cho phù hợp. 


\section{Kết luận và hàm ý quản trị}

\subsection{Kết luận}

Nghiên cứu đã đạt được mục tiêu khi xác định năm nhân tố ảnh hưởng đến ý định khởi nghiệp của sinh viên Trường Đại học Tiền Giang thông qua phân tích dữ liệu của 270 phiếu khảo sát sinh viên năm cuối. Các nhân tố ảnh hưởng bao gồm: đặc điểm tính cách, giáo dục khởi nghiệp, kinh nghiệm, nhận thức kiểm soát hành vi và quy chuẩn chủ quan. Cùng với nguồn vốn thì thái độ đối với hành vi - một trong ba yếu tố của thuyết hành vi dự định của Ajzen (1991) lại không có ý nghĩa thống kê. Kết quả nghiên cứu sẽ là cơ sở lý luận cho các nghiên cứu khác cùng lĩnh vực được thực hiện sau này. Ngoài ra, nghiên cứu cũng có một ý nghĩa thực tiễn quan trọng đối với nhà trường trong việc mang đến cái nhìn toàn diện, mới mẻ về ý định khởi nghiệp của sinh viên, từ đó đề ra những chính sách thích hợp nhằm phát huy hơn nữa tinh thần khởi nghiệp đúng đắn trong sinh viên thời gian tới.

\subsection{Hàm ý quản trị}

Một số hàm ý quản trị được đề xuất để nâng cao ý định khởi nghiệp của sinh viên:

\subsubsection{Xét về đặc điểm tính cách}

Việc phát triển những đặc điểm tính cách chủ động cho sinh viên cần được chú trọng và tập trung vào các khía cạnh như bản lĩnh đối mặt với trở ngại, thích được thử thách và dám chấp nhận rủi ro. Các hoạt động ngoại khóa nên được nhà trường tổ chức mới hơn, không chỉ đơn thuần mang tính giải trí mà còn mang đến cho sinh viên cảm giác được thử thách chính mình. Bên cạnh những nỗ lực của nhà trường thì sự cố gắng rèn luyện và trau dồi của chính sinh viên là điều không thể thiếu. Sinh viên phải mạnh dạn tham gia nhiều phong trào, cọ xát thực tế thì mới có được bản lĩnh vượt qua mọi rào cản.

\subsubsection{Xét về giáo dục khởi nghiệp}

Các lớp tập huấn "khởi sự kinh doanh" phải hướng đến sinh viên nhiều ngành chứ không chỉ dành riêng cho sinh viên kinh tế. Và các lớp này cũng cần được đổi mới theo hướng gia tăng thời lượng kết hợp nâng cao chất lượng và có cấp chứng nhận, thay vì chỉ là các lớp ngắn hạn 03 - 05 ngày như hiện nay. Ngoài ra, định hướng xây dựng riêng một chương trình đào tạo "Quản trị khởi nghiệp" cũng cần được nhà trường xem xét. Nhà trường phải xác định rõ giảng dạy khởi nghiệp không chỉ đơn thuần là truyền đạt kiến thức, kỹ năng, kinh nghiệm kinh doanh mà còn phải truyền được nhiệt huyết, sự yêu thích và đam mê.

\subsubsection{Xét về kinh nghiệm}

Nhà trường cần chú trọng hỗ trợ sinh viên nhiều hơn trong việc giới thiệu việc làm thêm cũng như quản lý việc làm thêm để sinh viên tích lũy kinh nghiệm. Sự phối hợp giữa nhà trường và doanh nghiệp là rất cần thiết nhằm xây dựng nhiều hơn các chương trình thực tập sinh, kiến tập kinh doanh tại các công ty, doanh nghiệp. Kế hoạch thành lập một câu lạc bộ khởi nghiệp cần được nhà trường xem xét. Đó sẽ là mái nhà chung cho những sinh viên yêu thích kinh doanh và muốn rèn luyện, phát triển bản thân với những kỹ năng, kiến thức kinh doanh hữu ích.

\subsubsection{Xét về nhận thức kiểm soát hành vi}

Nhận thức tích cực, đúng đắn về khả năng đối với khởi nghiệp rất quan trọng. Để có thể hỗ trợ sinh viên về vấn đề này thì định hướng giảng dạy dự án kinh doanh hay kế hoạch khởi nghiệp kinh doanh của nhà trường hiện tại cần thay đổi theo hướng thiết thực hơn khi mô phỏng một dự án thực tế và giảm lý thuyết. Riêng bản thân sinh viên cũng phải dành thời gian nghiên cứu thêm về các kiến thức kinh doanh liên quan, đặc biệt cập nhật những quy định mới của Nhà 
nước về việc thành lập doanh nghiệp, hỗ trợ doanh nghiệp khởi nghiệp, ...

\subsubsection{Xét về quy chuẩn chủ quan}

Đây là yếu tố mang tính chất xã hội nên vai trò của các tổ chức đoàn thể rất quan trọng. Các hoạt động tuyên truyền hay thực hiện tọa đàm nêu gương những doanh nhân khởi nghiệp thành công sẽ giúp khởi nghiệp được biết đến một cách rộng hơn và được hiểu một cách đúng đắn hơn, từ đó sự ủng hộ của mọi người dành cho khởi nghiệp sẽ tăng lên. Tiền Giang rất cần một "Trung tâm hỗ trợ thanh niên khởi nghiệp" do tỉnh đoàn và đoàn Trường Đại học Tiền Giang phối hợp thành lập. Có như vậy, khởi nghiệp không còn bị coi là một hoạt động ngẫu hứng, tự phát mà là một hoạt động được sự quan tâm, hỗ trợ của các cơ quan chức năng, từ đó sự ủng hộ khởi nghiệp cũng được nâng cao.

\section{Tài liệu tham khảo}

Ajzen, I. (1991). The theory of planned behavior. Organizational Behavior and Human Decision Processes, 50(2), 179-211.

Ambad, S. N. A., \& Damit, D. H. D. A. (2016). Determinants of entrepreneurial intention among undergraduate students in Malaysia. Procedia Economics and Finance, 37(2016), 108-114.

Amos, A., \& Alex, K. (2014). Theory of planned behaviour, contextual elements, demographic factors and entrepreneurial intentions of students in Kenya. European Journal of Business and Management, 6(15), 167-175.

Armitage, C. J., \& Conner, M. (2001). Efficacy of the theory of planned behavior : A metaanalytic review. British Journal of Social Psychology, 40(4), 471-499.

Autio, E., Keeley, R. H., Klofsten, M., Parker, G. G. C., \& Hay, M. (2001). Entrepreneurial intent among students in Scandinavia and in the USA. Enterprise and Innovation Management Studies, 2(2), 145-160.

Bird, B. (1988). Implementing entrepreneurial ideas: The case for intention. Academy of Management Review, 13(3), 442-453.

Devonish, D., Alleyne, P., Charles-Soverall, W., Young, Marshall, A., \& Pounder, P. (2010). Explaining entrepreneurial intentions in the Caribbean. International Journal of Entrepreneurial Behavior \& Research, 16(2), 149-171.

Do, L. T. H. (2016). Các nhân tố ảnh hưởng đến ý định khởi nghiệp kinh doanh của sinh viên quản trị kinh doanh tại trường Đại học Lao động - Xã hội (cơ sở thành phố Hồ Chí Minh) [Factors affecting the intention to start a business of business administration students at the University of Labor and Social Affairs (Ho Chi Minh City campus)]. Tap chi khoa hoc Yersin, 1, 44-53.

Dohse, D., \& Walter, S. G. (2012). Knowledge context and entrepreneurial intentions among students. Small Business Economics, 39(4), 877-895.

Gird, A., \& Bagraim, J. J. (2008). The theory of planned behaviour as predictor of entrepreneurial intent amongst final-year university students. South African Journal of Psychology, 38(4), 711-724.

Hisrich, R. D., \& Drovensek, M. (2002). Entrepreneurship and small business research: A european perspective. Journal of Small Business and Enterprise Development, 9(2), 171-222. 
Hoang, T. T. P., \& Bui, C. T. T. (2013). Ý định khởi nghiệp của nữ học viên MBA tại TP. Hồ Chí Minh [The intention of starting a business of female MBA students in Ho Chi Minh City]. Tạp chi Phát triển Kinh tế, 271(2013), 10-12.

Hoang, T., \& Chu, N. N. M. (2008). Phân tích dũ liệu nghiên cúu với SPSS [Analyze research data with SPSS]. Ho Chi Minh, Vietnam : Nhà xuất bản Hồng Đức.

Isaacs, E., Visser, K., Friedrich, C., \& Brijlal, P. (2007). Entrepreneurship education and training at the Further Education and Training (FET) level in South Africa. South African Journal of Education, 27(4), 613-629.

Karabulut, A. T. (2016). Personality traits on entrepreneurial intention. Procedia - Social and Behavioral Sciences, 229(2016), 12-21.

Kickul, J., \& Gundry, L. (2002). Prospecting for strategic advantage: The proactive entrepreneurial personality and small firm innovation. Journal of Small Business Management, 40(2), 85-97.

Koe, W. L., Sa'ari, J. R., Majid, I. A., \& Ismail, K. (2012), Determinants of entrepreneurial intention among millennial generation. Procedia - Social and Behavioral Sciences, 40(2012), 197-208.

Krueger, N. F., \& Brazeal, D. V. (1994). Entrepreneurial potential and potential entrepreneurs. Entrepreneurship Theory and Practice, 18(3), 91-104.

Kuckertz, A., \& Wagner, M. (2010). The influence of sustainability orientation on entrepreneurial intentions - Investigating the role of business experience. Journal of Business Venturing, 25(5), 524-539.

Kuratko, D. F. (2005). The emergence of entrepreneurship education : Development, trends, and challenges. Entrepreneurship Theory and Practice, 29(5), 577-598.

Liñán, F., \& Chen, Y. W. (2009). Development and cross-cultural application of a specific instrument to measure entrepreneurial intentions. Entrepreneurship Theory and Practice, 33(3), 593-617.

Liñán, F., Rodríguez-Cohard, J. C., \& Rueda-Cantuche, J. M. (2011). Factors affecting entrepreneurial intention levels: A role for education. International Entrepreneurship and Management Journal, 7(2), 195-218.

Lüthje, C., \& Franke, N. (2003). The 'making'of an entrepreneur: Testing a model of entrepreneurial intent among engineering students at MIT. R\&D Management, 33(2), 135147.

MacMillan, I. C. (1993). The emerging forum for entrepreneurship scholars. Journal of Business Venturing, 8(5), 377-381.

Mazzarol, T., Volery, T., Doss, N., \& Thein, V. (1999). Factors influencing small business startups: A comparison with previous research. International Journal of Entrepreneurial Behavior \& Research, 5(2), 48-63.

Nga, J. K. H., \& Shamuganathan, G. (2010). The influence of personality traits and demographic factors on social entrepreneurship start up intentions. Journal of Business Ethics, 95(2), 259-282.

Nguyen, T. D. (2011). Phưong pháp nghiên cúu khoa học trong kinh doanh [Scientific research methods in business]. Ho Chi Minh City, Vietnam: Nhà xuất bản Lao động xã hội. 
Nguyen, T. T. (2015). Nghiên cưu các nhân tố ảnh hưởng tới tiềm năng khởi sự kinh doanh của sinh viên đại họ [Research on factors influencing college students' entrepreneurial potential]. (Unpublished doctoral dissertation). National Economics University, Hanoi, Vietnam.

Obschonka, M., Silbereisen, R. K., \& Schmitt-Rodermund, E. (2010). Entrepreneurial intention as developmental outcome. Journal of Vocational Behavior, 77(1), 63-72.

Phan, T. A., \& Giang, T. T. C. (2015). Nghiên cứu các nhân tố ảnh hưởng đến ý định khởi sự doanh nghiệp: Trường hợp sinh viên Khoa Kinh tế và Quản trị kinh doanh trường Đại học Cần Thơ [Research on factors affecting the intention to start a business: The case of students of the Faculty of Economics and Business Administration, Can Tho University]. Tạp chi Khoa học Trường Đại học Cần Tho, 40(2015), 59-66.

Phòng Công tác sinh viên Trường Đại học Tiền Giang. (2019). Báo cáo tình hình học tập của sinh viên hoc kỳ 1 năm hoc 2019 - 2020 [Report on the learning situation of students in the first semester of the academic year 2019-2020]. Tien Giang, Vietnam: Phòng Công tác sinh viên Trường Đại học Tiền Giang.

Rasli, A. M., Khan, S. U. R., Malekifar, S., \& Jabeen, S. (2013). Factors affecting entrepreneurial intention among graduate students of Universiti Teknologi Malaysia. International Journal of Business and Social Science, 4(2), 182-188.

Sabah, S. (2016). Entrepreneurial intention: Theory of planned behaviour and the moderation effect of start-up experience. In M. Franco (Ed.), Entrepreneurship-practice - Oriented perspectives (pp. 87-101). doi:10.5772/65640

Shapero, A., \& Sokol, L. (1982). Some social dimensions of entrepreneurship. In C. A. Kent (Ed.), Encyclopedia of entrepreneurship (pp. 72-90). Englewood Cliffs, NJ: Prentice-Hall.

Souitaris, V., Zerbinati, S., \& Al-Laham, A. (2007). Do entrepreneurship programmes raise entrepreneurial intention of science and engineering students? The effect of learning, inspiration and resources. Journal of Business Venturing, 22(4), 566-591.

Suan, C. T., Ai, Y. J., Raman, K., Loon, K. W., \& Tanumihardja, J. (2011). Entrepreneurial intentions among university students. Business \& Management Quarterly Review, 2(3), 33-38.

Thủ Tướng Chính phủ. (2017). Quyết định số 1665/QĐ-TTg ngày 30 tháng 10 năm 2017 về việc phê duyệt đề án "Hỗ trọ" học sinh, sinh viên khởi nghiệp đến năm 2025" [Decision No. 1665/QD-TTg dated October 30, 2017 approving the project "Supporting students and students to start a business by 2025"]. Retrieved May 10, 2020, from https://thuvienphapluat.vn/van-ban/giao-duc/quyet-dinh-1665-qd-ttg-2017-de-an-ho-trohoc-sinh-sinh-vien-khoi-nghiep-den-nam-2025-365846.aspx

Turker, D., \& Selcuk, S. S. (2009). Which factors affect entrepreneurial intention of university students? Journal of European Industrial Training, 33(2), 142-159.

Wang, C. K., \& Wong, P. K. (2004). Entrepreneurial interest of university students in Singapore. Technovation, 24(2), 163-172.

Zain, Z. M., Akram, A. M., \& Ghani, E. K. (2010). Entrepreneurship intention among malaysian business students. Canadian Social Science, 6(3), 34-44.

Zhang, Y., Duysters, G., \& Cloodt, M. (2014). The role of entrepreneurship education as a predictor of university students' entrepreneurial intention. International Entrepreneurship and Management Journal, 10(3), 623- 641. 